\title{
Youth Mentoring: Involving College Students ${ }^{1}$
}

\author{
Emily Rickerson, Muthusami Kumaran, and Kate Fogarty ${ }^{2}$
}

\section{Introduction}

Today's youth are facing a number of troubling issues including substance abuse, family disturbances, bullying, low morale resulting in low academic achievement, dropping out of school, and more. Having someone who cares about youth, to talk to them about the issues they face and mentoring them, can be a positive factor for all involved.

In 2008, law enforcement agencies made an estimated 2.11 million juvenile (persons under the age of 18) arrests in the United States (U.S. Department of Justice, 2009). From October 2006 to October 2007, three and one-half of every 100 students who were enrolled in public or private high schools in the nation left school before graduating (U.S. Department of Education, 2009). Results from the 2009 National Youth Risk Behavior Surveillance Survey indicated that among high school students nationwide, during the 30 days before the survey, $28.3 \%$ of high school students rode in a vehicle driven by someone who had been drinking alcohol, $17.5 \%$ had carried a weapon, $41.8 \%$ had drunk alcohol, and $20.8 \%$ had smoked marijuana. During the 12 months before the survey, $31.5 \%$ of high school students had been in a physical fight and $6.3 \%$ had attempted suicide (YRBSS, 2009). These disturbing trends, left unchecked, can result in dire consequences (e.g., jail time, financial troubles, and poor health) compromising the future of our youth and our society.

\section{The Role of Mentoring}

Mentors give support to at-risk children in need. According to the journal article "Mentors: Beacons of Hope," a mentor is defined as "one who listens to, cares for, gives advice to, and shares information and life/career experiences with another, especially a young person requiring assistance" (Dondero, 1997, p. 882).

A great way to teach college students to be successful mentors is to involve them in service learning. Service learning involves reflection as well as action and combines community work with classroom instruction and course requirements (Schutz \& Gere, 1998). Service learning has been seen shown to foster self-efficacy, leadership skills, and a sense of civic responsibility and community participation in college students (Vogelgesang \& Astin, 2000).

One model service-learning mentoring program is University of Florida's Collegiate Achievement Mentoring Program, C.A.M.P. (Collegiate Achievement Mentoring Program) Gator, launched in 2008. C.A.M.P. Gator is a unique mentoring program in that it places emphasis on the teaching, nurturing, and growth of the mentors as well as the mentees. It combines collegiate-level coursework with service in the community and teaches students how to be leaders, role models, and successful mentors. It also teaches them the importance of making a difference in their community. Mentoring is a mutually beneficial action and C.A.M.P. Gator concentrates on building college students' character in areas of leadership, civic responsibly, and other self-development skills. These skills help them become

1. This document is FCS9266, one in a series of the Department of Family, Youth and Community Sciences, Florida Cooperative Extension Service, Institute of Food and Agricultural Sciences, University of Florida. Published August 2011. Visit the EDIS website at http://edis.ifas.ufl.edu.

2. Emily Rickerson, graduate assistant; Muthusami Kumaran, assistant professor; Kate Fogarty, assistant professor; Department of Family, Youth and Community Sciences; Institute of Food and Agricultural Sciences; University of Florida; Gainesville, FL 32611. 
better mentors for the students they are mentoring, as well as prepare them for life outside of college.

\section{Impacts of Mentoring}

Mentoring programs, such as C.A.M.P. Gator, have been shown to have positive impacts on the youth they serve. Data from C.A.M.P. Gator's first year of existence, 2008-2009, showed a:

- $13 \%$ increase in GPA,

- $22 \%$ increase in attendance, and

- $72 \%$ decrease in suspensions for mentees.

Youth involved as mentees in the Big Brothers, Big Sisters program have been reported to be:

- $46 \%$ less likely to have started using illegal drugs,

- $27 \%$ less likely to have started using alcohol, and

- of a mindset where they typically felt more competent about doing schoolwork than those youth who were not participants in the program (Grossman \& Tierney, 1998).

Mentoring programs have also demonstrated their ability to exercise a major impact on the reduction of dropout rates among children from elementary to high school. The National Dropout Prevention Center at Clemson University identified several significant risk factors that notably increase the likelihood of students dropping out of school and subsequently identified exemplary, evidence-based programs that addressed these risk factors. Mentoring programs were seen to be among the best practices in dealing with the following risk factors for students (National Dropout Prevention Center, 2007):

- high-risk social behavior

- poor academic performance

- poor attendance

- family structure

- family disruption

The positive impacts of mentoring extend beyond benefits to just the mentee-it is also beneficial for the mentors. A study conducted on a group of college-age mentors who participated in a mentoring program for local at-risk fourth-graders concluded with positive feedback about the mentor's experiences: "At the end of the academic year, mentors reported that mentoring taught them important lessons about children, themselves, community work and the value of mentoring" (Schmidt, Marks \& Derrico, 2004, p. 205). Similarly, the C.A.M.P. Gator program also showed positive outcomes for the mentors involved, with data reporting increased public-speaking abilities, goal-setting aptitude, and leadership skills for participating mentors.

\section{Conclusion}

Mentoring contributes to positive outcomes for both mentors and mentees. Involving college students in a service-learning mentoring program can be beneficial in fostering healthy growth for at-risk youth as well as for college students involved in the program. Model mentoring programs such as C.A.M.P. Gator can be a unique way to engage college students in mentoring and community involvement. Programs such as these can be replicated in institutions of higher education across the nation that have an interest in youth development and service.

\section{References}

C.A.M.P. Gator Website (2010). Program Data 2008-2009. Retrieved November 18, 2010 from http://www.campgator. com/data.html.

Dondero, G.M. (1997). Mentors: Beacons of hope. Adolescence 32(128): 881-886.

Grossman, J.B., \& Tierney, J.P. (1998). Does mentoring work? An impact study of the Big Brothers, Big Sisters program. Evaluation Review 22(3): 403-426.

National Dropout Prevention Center at Clemson University and Communities in Schools, Inc. (2007). Dropout Risk Factors and Exemplary Programs, A Technical Report. Retrieved November 16, 2010 from http://www.dropoutprevention. org/sites/default/files/uploads/major_reports/DropoutRiskFactorsandExemplaryProgramsFINAL5-16-07.pdf.

Schmidt, M., Marks, J., \& Derrico, L. (2004). What a difference mentoring makes: Service learning and engagement for college students. Mentoring \& Tutoring: Partnership in Learning 12(2): 205-217.

Schutz, A., \& Gere, A. (1998). Service learning and English studies: Rethinking "public" service. College English 60(2): 129-149. 
U.S. Department of Justice. (2009). Juvenile arrests, 2008. Office of Juvenile Justice and Delinquency Prevention, 2009. Retrieved November 17, 2010 from http://www.ncjrs.gov/ pdffiles1/ojjdp/228479.pdf.

Vogelgesang, L., \& Astin, A. (2000). Comparing the Effects of Community Service and Service-Learning. Michigan Journal of Community Service Learning 7(1): 25-34.

YRBSS. (2009). U.S. Department of Health And Human Services, Centers for Disease Control and Prevention. Youth Risk Behavior Surveillance Survey United States, 2009. Retrieved November 18, 2010 from http://www.cdc.gov/ mmwr/pdf/ss/ss5905.pdf. 